JANO $71991 \quad$ DE91 005917

\title{
EXPERIMENTAL STUDIES OF PLASMA FLUCTUATIONS USING ELECTRON CYCLOTRON EMISSION ON ATF AND TEXT
}

\author{
Progress Report
}

\author{
Rex Gandy \\ Physics Department \\ Auburn University \\ Auburn, Alabama 36849
}

November 1990

\section{DISCLAIMER}

\begin{abstract}
This report was prepared as an account of work sponsored by an agency of the United States Government. Neither the United States Government nor any agency thereof, nor any of the:employees, makes any warranty, express or implied, or assumes any legal liability or responsibility for the accuracy, completeness, or usefulness of any information, apparatus, product, or process disclosed, or represents that its use would not infringe privately owned rights. Reference herein to any specific commercial product, process, or service by trade name, trademark, manufacturer, or otherwise does not necessarily constitute or imply its endorsement, recommendation, or favoring by the United States Government or any agency thereof. The views and opinions of authors expressed herein do not necessarily state or reflect those of the United States Government or any agency thereof.
\end{abstract}

PREPARED FOR THE US DEPARTMENT OF ENERGY UNDER GRANT NUMBER DE-FGO5-90ER54085

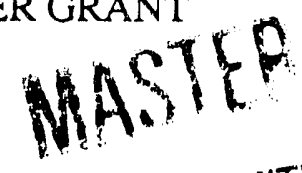

$$
\text { DISTRIBUTION OF THIS DOCUMEIVT }
$$




\begin{abstract}
The great stumbling block in the quest for fusion power using magnetic confinement devices is anomalous transport. It is conjectured that turbulent plasma fluctuations may be responsible for the degraded energy confinement observed in experiments. There exists a clear need for more detailed experimental studies of plasma microturbulence. We have started a set of experiments to measure electron temperature and density fluctuations using electron cyclotron emission (ECE). The ECE systems will employ auto-correlation and cross-correlation techniques to measure radiation from the Advanced Toroidal Facility (ATF) at Oak Ridge National Laboratory (ORNL) and also from the Texas Experimental Tokamak (TEXT) at the University of Texas. This set of experiments on a stellarator and a tokamak will allow a unique comparative study of the fluctuation physics in the two different magnetic configurations. This work is in support of the United States Department of Energy Tokamak Transport Initiative and invo' res a collaborative effort between Auburn University, Georgia Institute of Technology, the University of Texas at Austin and ORNL.
\end{abstract}




\section{Motivation}

In the quest for controlled thermonuclear fusion, the magnetic confinement approach has encountered a formidable obstacle: namely, anomalous transport. The experimental values of electron thermal diffusivity exceed those expected from neoclassical theory by orders of magnitude. There clearly exists a lack of understanding of thermal transport in high temperature plasma devices. It is conjectured that fine-scale plasma microinstabilities may be the cause of the anomalous transport [1-3]. Currently no accepted theory exists which can fully explain the experimental results obtained. One of the causes of this lack of understanding is the past and present experimental emphasis on measuring bulk, time-averaged plasma quantities. Clearly, in order for the plasma community to understand the basic physics of anomalous transport, experimentalists need to design dedicated plasma diagnostics to measure the fluctuating component of particular plasma quantities.

Electron cyclotron emission (ECE) has the potential to provide information on fluctuations in electron temperature, electron density and magnetic field. Initially, our experiments will focus on the detection of optically thick, second harmonic ECE to look at fluctuations in electron temperature. We have commenced a set of experiments to measure fluctuating ECE from the ATF stellarator located at ORNL and TEXT at the University of Texas(a moderate sized tokamak). This use of a tokamak and a stellarator will lead to insights into the similarities and differences of transport in the two main classes of toroidal devices. This project is a collaborative effort between Auburn University, Georgia Institute of Technology, the University of Texas at Austin and ORNL 


\section{Progress To Date}

The research on the ATF/TEXT fluctuating ECE diagnostic system has progressed considerably during the past eight months. Approximately ninety per cent of the necessary hardware has been ordered ( with all the long lead time items ordered). A post-doctoral associate, Dr. Myeun Kwon, was hired in September 1990. He is presently working on the design and implementation of the ATF system. At the present pace, and assuming no extraordinary order delays, we expect to have all of the hardware for the ATF experiment in hand by March 1991. We plan to have our first ATF data by summer 1991. The present research plan calls for the implementation of the TEXT phase of the project in fall 1991. Dr. Kwon will move to Austin at this time to expedite this phase of the research. A graduate student will continue with the experimental program on ATF. During the second year comparative studies will commence to explore tokamak versus stellarator fluctuation physics.

Professors Thomas and Gandy will continue to act as co-leaders of the research project. Both will be actively involved in all aspects of the physics studies, system design and installation and project management. Several trips needed for planning the experiment have been made to ORNL and the Univ. of Texas during the past year. The port location and relevant vacuum interfacing decisions have been completed for the ATF part of the project. The TEXT diagnostic interfacing decisions are also completed.

The post-doctoral associate will have primary responsibility for the on-site, day-to day operation of the diagnostic systems. A graduate student will also be employed. A list of relevant publications associated with the project is included as Appendix I. 


\section{REFERENCES}

1. L.A Artsimovich, Nucl. Fusion 12, p. 215 (1972).

2. H.P. Furth, Nucl. Fusion 15, p. 487 (1985).

3. P.C. Liewer, Nucl. Fusion ,25, no. 5, p. 543 (1985). 
APPENDIX I.

\section{List of Recent Publications}

1988-1990

1. Thomas, Hanson, Gandy, Batchelor and Goldfinger ; "Conceptual Design and Numerical Simulation of a Correlation Diagnostic for Measurement of Magnetic Fluctuations in Plasmas", Review of Scientific Instruments, 59 (9),p. 1644, Sept. 1988.

2. Thomas and Gandy ; "Autocorrelation and Cross-Sightline Correlation of ECE for Measurement of Electron temperature and Density Fluctuations on ATF and TEXT", Review of Scientific Instruments, Nov.1990. 

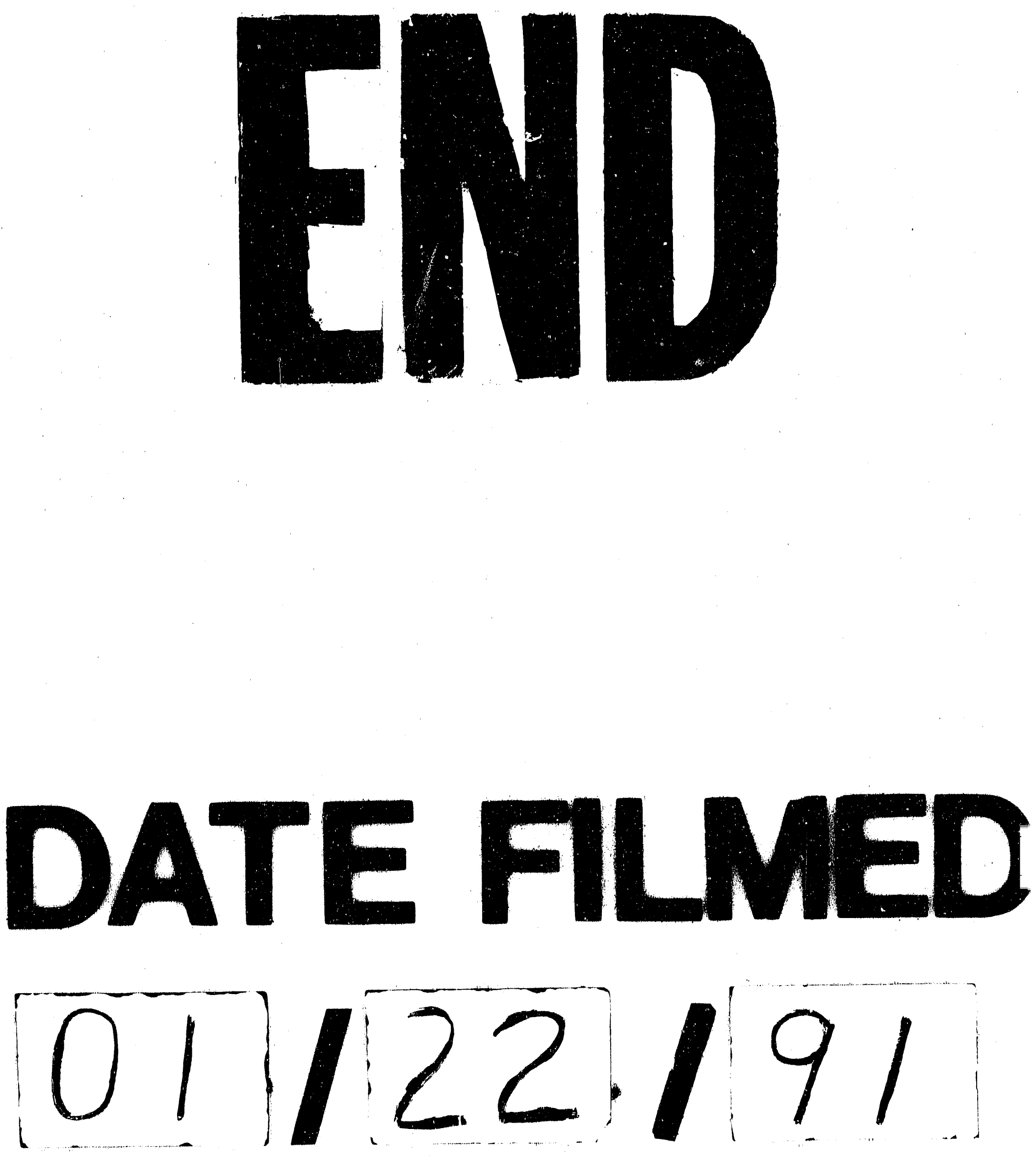
